\title{
Импедансная спектроскопия пористых кремниевых и кремний-углеродных анодов, полученных спеканием
}

\author{
(ㄱ Д.А. Ложкина, А.М. Румянцев, Е.В. Астрова \\ Физико-технический институт им. А.Ф. Иофрфе Российской академии наук, \\ 194021 Санкт-Петербург, Россия \\ E-mail: darina.lozhka94@gmail.com, east@mail.ioffe.ru
}

Поступила в Редакцию 29 октября 2019 г.

В окончательной редакции 5 ноября 2019 г.

Принята к публикации 5 ноября 2019 г.

\begin{abstract}
Спеченные всухую макропористые Si-электроды для Li-ионных аккумуляторов впервые изучаются с помощью спектральной импедансометрии. Полученные спектры в литированном и делитированном состояниях моделируются эквивалентной электрической схемой, параметры которой позволяют вычленить роль электрохимических процессов, обусловленных поверхностным слоем твердофазного электролита (SEI), двойным электрическим слоем и диффузией в твердой фазе материала электрода. Показано, что эффективный коэффициент диффузии $\mathrm{Li}$ в $\mathrm{Si}$ увеличивается по мере возрастания степени литирования от $D=6.5 \cdot 10^{-12}$ до $2.6 \cdot 10^{-10} \mathrm{~cm}^{2} /$. Изучено влияние карбонизации, проводившейся путем пиролиза сахарозы, которая привела к снижению импеданса и возрастанию коэффициента диффузии лития до $D=2.2 \cdot 10^{-10}-1.7 \cdot 10^{-9} \mathrm{~cm}^{2} / \mathrm{c}$.
\end{abstract}

Ключевые слова: литий-ионные аккумуляторы, электрохимическая импедансная спектроскопия, кремниевые аноды, карбонизация, коэффициент диффузии лития в кремнии.

DOI: 10.21883/FTP.2020.03.49039.9299

\section{1. Введение}

Кремний является перспективным материалом для отрицательных электродов литий-ионных аккумуляторов (ЛИА), поскольку обладает наиболее высоким значением удельной гравиметрической емкости (4200 мА - ч/г), низким потенциалом внедрения $\mathrm{Li}(0.2-0.3 \mathrm{~B})$ и широко распространен в земной коре. Недостатками являются большое изменение объема при литировании, низкая скорость заряда-разряда из-за малого коэффициента диффузии $\mathrm{Li}$ и нестабильность поверхностной пленки SEI (solid electrolyte interface) [1]. Способом, позволяющим снизить скорость деградации кремниевых электродов и повысить их скоростные характеристики, является формирование наноструктурированного материала с субмикрометровыми размерами элементов [2], в том числе макропористого кремния, состоящего из проволок или плоскостей, сохраняющих структуру монокристалла $[3,4]$. В процессе интенсивного исследования новых анодных материалов, происходящего во всем мире, показано, что значительного улучшения характеристик кремниевых электродов можно достичь путем формирования композитов. Среди них кремний-углеродные композиты представляют наибольший интерес, поскольку позволяют обеспечить высокую емкость, высокую электронную проводимость и стабильность при циклировании $[5,6]$.

Для исследования кинетики процессов с участием лития широко применяется метод электрохимической импедансной спектроскопии (electrochemical impedance spectroscopy, EIS) [7-10]. В частности, с его помощью можно найти коэффициент диффузии лития, который является важнейшим фактором, определяющим скоростные способности (время заряда и разряда батареи). При электрохимическом литировании кремния образуются сплавы $\mathrm{Li}_{x} \mathrm{Si}$ с высоким содержанием лития вплоть до $x=4.4$. Таким образом, диффузия Li происходит в среде переменного состава, который влияет на мобильность диффундирующих атомов. Измеренный в таких условиях коэффициент диффузии является концентрационнозависимой величиной, и для него используется термин химический, или эффективный, коэффициент диффузии $D[11]$. Для корректного нахождения $D$ стараются использовать электроды из чистого кремния без дополнительных компонент, чаще всего в виде пленок аморфного $\mathrm{Si}[12,13]$.

Недавно нами была исследована возможность изготовления макропористого кремния путем холодной компрессии и высокотемпературного спекания нанопорошка $\mathrm{Si}$ в инертной атмосфере [14]. Свойства полученного материала и изготовленных из него анодов находятся в зависимости от структуры, которая в первую очередь определяется температурой и длительностью отжига при спекании. Электроды с оптимальной структурой имели стабильное значение емкости $Q=1000 \mathrm{MA} \cdot$ ч/г (> 120 циклов при скорости заряда-разряда $\mathrm{C} / 5$ ) и ее снижение до $890 \mathrm{MA} \cdot$ ч/Г при повышении скорости делитирования до $1 \mathrm{C}$ (C - единица скорости зарядаразряда аккумулятора) [15]. Макропористый $\mathrm{Si}$, полученный спеканием, обладает кристаллической структурой и является удобным объектом для исследования методом $\mathrm{EIS}$, так как в отличие от монолитного материала, достаточно долго не разрушается при циклическом внедрении и экстракции лития.

В настоящей работе ставилась задача исследовать методом EIS кинетические параметры спеченных $\mathrm{Si}$-электродов в литированном и делитированном состояниях, а также влияние на них карбонизации. 

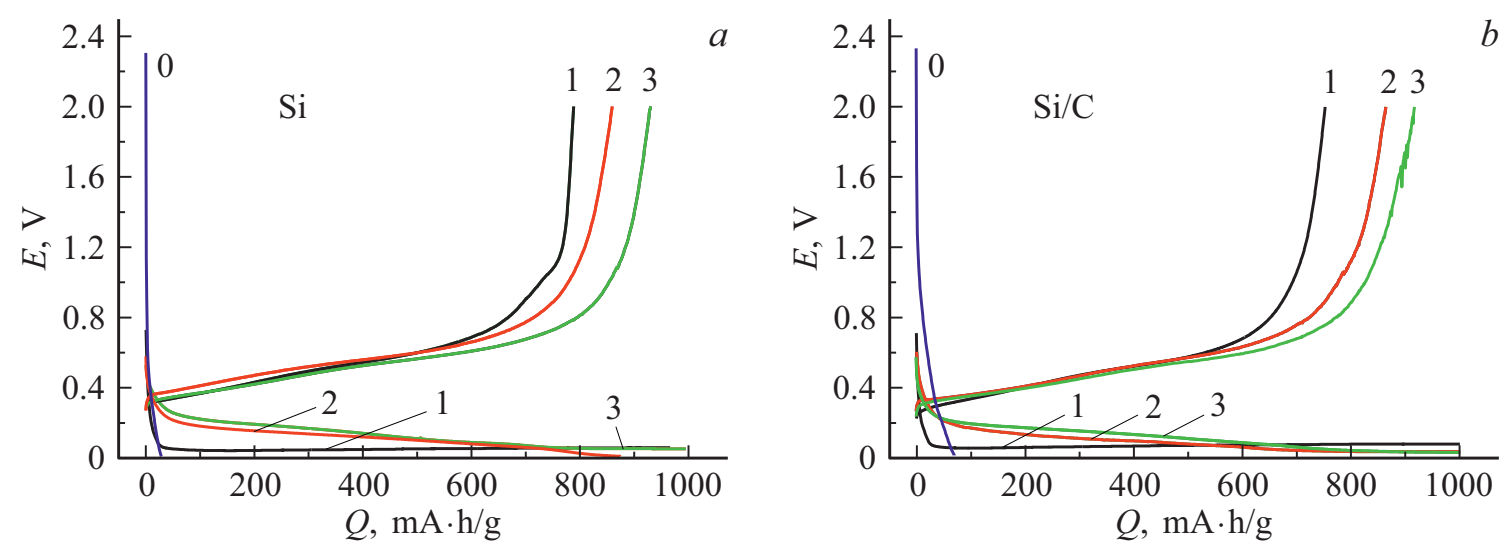

Рис. 1. Зарядно-разрядные кривые для электродов из $\mathrm{Si}(a)$ и $\mathrm{Si} / \mathrm{C}(b)$. Указаны номера циклов $1,2,3$.

\section{2. Методика эксперимента}

Исходным материалом служил нано порошок Si (коммерческий продукт Hongwu Nanometer), состоящий из кристаллических частиц диаметром $30-50$ нм. Путем холодной компрессии всухую (без связующего) при давлении 180 МПа формировали таблетки диаметром 6 мм и толщиной $\sim 500$ мкм. Спекание таблеток проводилось при температуре $T=1150^{\circ} \mathrm{C}$ в течение 1 ч в потоке аргона, в результате происходило укрупнение кремниевых зерен до $150-200$ нм и образование связной токопроводящей матрицы. Гравиметрическую пористость $p$ таблеток определяли из измеренной плотности $\rho$ как $p=\left(1-\rho / \rho_{m}\right) \cdot 100 \%$, где $\rho_{m}=2.33 \mathrm{r} / \mathrm{cm}^{3}-$ плотность монолитного кремния. Измерение удельного электрического сопротивления таблеток $\rho_{\mathrm{el}}$ проводилось четырехзондовым методом. Площадь внутренней поверхности была определена по изотерме адсорбции азота методом БЭТ (Браунера, Эммета, Теллера) и составила $18.6 \mathrm{M}^{2} / \Gamma$ [14].

Часть спеченных таблеток пропитывалась 45.5\%-м водно-спиртовым раствором сахарозы при температуре $70^{\circ} \mathrm{C}$ в течение 3 ч. Пиролиз сахарозы проводился в Ar при $T=900^{\circ} \mathrm{C}$ в течение 1 ч. После карбонизации слой толщиной 20-30мкм удалялся с обеих сторон таблетки с помощью шлифовки. Содержание углерода в образцах $\mathrm{Si} / \mathrm{C}$ определялось методом энергодисперсионного рентгеновского микроанализа (EDX) и составляло $10-15 \%$ по массе, при этом сопротивление $\rho_{\mathrm{el}}$ падало на 3 порядка.

Для формирования электродов на одну из сторон таблеток $\mathrm{Si}$ или $\mathrm{Si} / \mathrm{C}$ осаждали гальваническую медь толщиной $\sim(20-30)$ мкм, после чего уменьшали толщину кремниевого слоя до $L \approx 85$ мкм. Электрохимические измерения проводили в лабораторной трехэлектродной ячейке, аналогичной по конструкции ячейке HS 3E (Hohsen), электрод сравнения и вспомогательный электрод которой были изготовлены из металлического лития. Электролитом служил ТC-E918 (Tinci), представляющий собой $1 \mathrm{M}$ раствор $\mathrm{LiPF}_{6}$ в смеси органиче-
Таблица 1. Параметры кремниевых и кремний-углеродных электродов

\begin{tabular}{l|c|c}
\hline Параметр & $\mathrm{Si}$ & $\mathrm{Si} / \mathrm{C}$ \\
\hline$L$, мкм & 83 & 86 \\
$m_{\mathrm{Si}}, \mathrm{M \Gamma}$ & 2.72 & 3.08 \\
$\rho_{\mathrm{el}}, \mathrm{OM} \cdot \mathrm{cm}$ & $4.1 \cdot 10^{4}$ & 45 \\
$\rho, \Gamma / \mathrm{cm}^{3}$ & 1.34 & 1.55 \\
$p, \%$ & 42.5 & 34 \\
$S, \mathrm{Mм}^{2}$ & 24.4 & 23.3
\end{tabular}

ских растворителей. Гальваностатический заряд и разряд ячейки осуществлялись на стенде CT3008W-5V $10 \mathrm{~mA}$ (Neware) при плотности тока $0.05 \mathrm{~A} / г$ на первом цикле и $0.1 \mathrm{~A} / \Gamma$ на последующих. Заряд (литирование) электродов ограничивался емкостью $Q=1000 \mathrm{MA} \cdot$ ч/г. При внедрении $\mathrm{Li}$ напряжение на исследуемом электроде относительно электрода сравнения ограничивалось напряжением $10 \mathrm{MB}$ и, при разряде (экстракции $\mathrm{Li}$ ) напряжением $E=2$ В. Измерения импеданса выполнялись с использованием модульного потенцио/гальваностата фирмы AUTOLAB модель PGSTAT302N (Metrohm) в диапазоне частот $v$ от 100 кГц до 0.01 Гц, амплитуда переменного напряжения составляла $5 \mathrm{mB}$. Для расчета спектров импеданса применялось программное обеспечение ZView (Scribner Associates Inc.). Параметры образцов, которые использовались для проведения импедансных измерений, приведены в табл. 1 , где $m_{\mathrm{Si}}-$ масса кремния или карбонизированного кремния, $S-$ номинальная площадь электрода.

\section{3. Результаты эксперимента}

На рис. 1 приведены зарядно-разрядные кривые исследованных образцов. Следует заметить, что попытка внедрить литий при токе $0.1 \mathrm{~A} /\ulcorner$ не увенчалась успехом, так как напряжение быстро упало до $10 \mathrm{MB}$. Соответствующие кривые на рис. $1, a, b$ обозначены как нулевой 

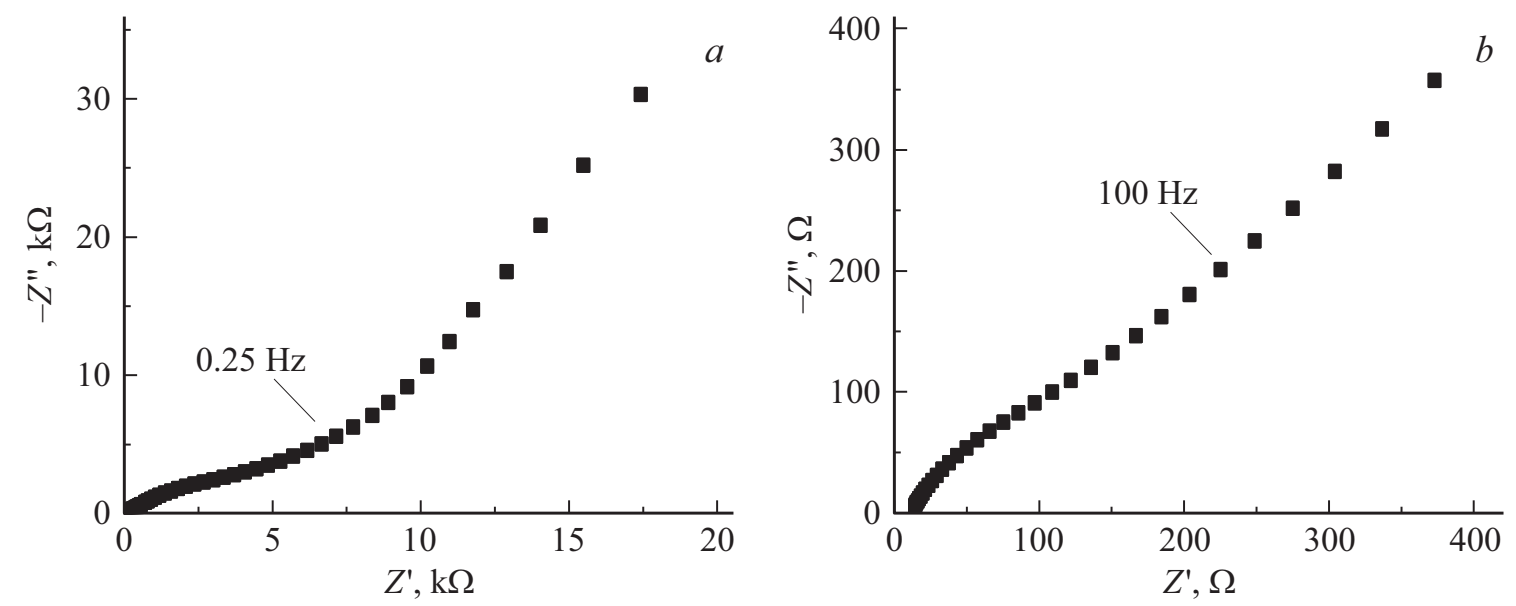

Рис. 2. Спектр импеданса нелитированного кремниевого электрода: $a-$ общий вид, $b-$ высокочастотная область годографа.
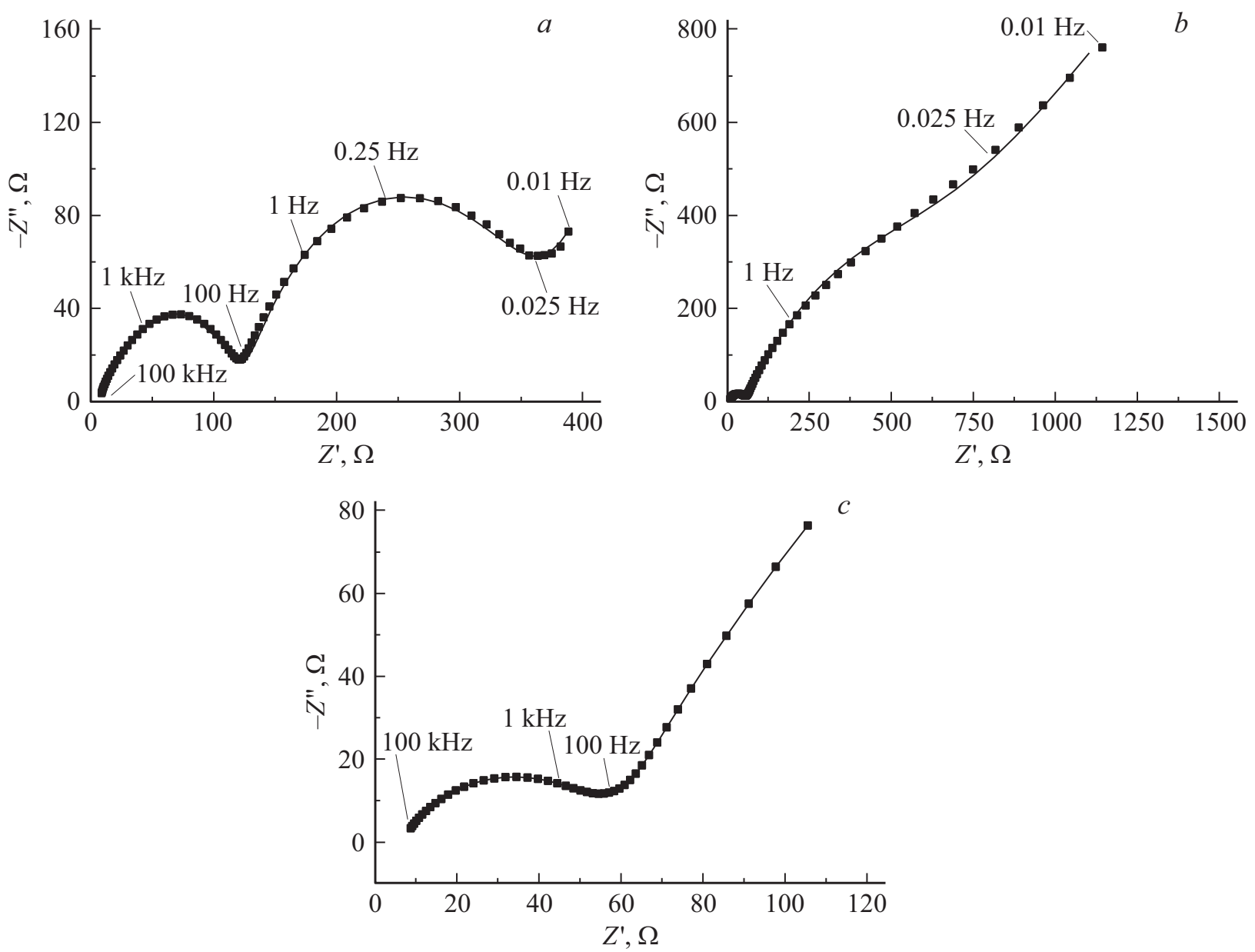

Pис. 3. Годографы импеданса Si-образца для первого цикла: $a$ - литированное состояние, $b$ - делитированное состояние; $c$ - высокочастотная область годографа в делитированном состоянии. Точки - экспериментальные данные, линии - результаты расчета эквивалентной схемы. Отмечены частоты $v$ переменного напряжения.

цикл (0). Поэтому первый цикл литирования-делитирования осуществлялся при токе $0.05 \mathrm{~A} /$ г. Видно, что кривая, соответствующая внедрению лития на первом цикле, имеет вид, характерный для кристаллического кремния, с резким падением напряжения и горизон- тальным плато [16]. Ее форма обусловлена двухфазным механизмом первого внедрения $\mathrm{Li}$, когда существует резкая граница между аморфным литированным слоем $a-\mathrm{Li}_{x} \mathrm{Si}$ и кристаллическим $c-\mathrm{Si}$ [17]. Скорость литирования в этом случае ограничивается реакцией на 

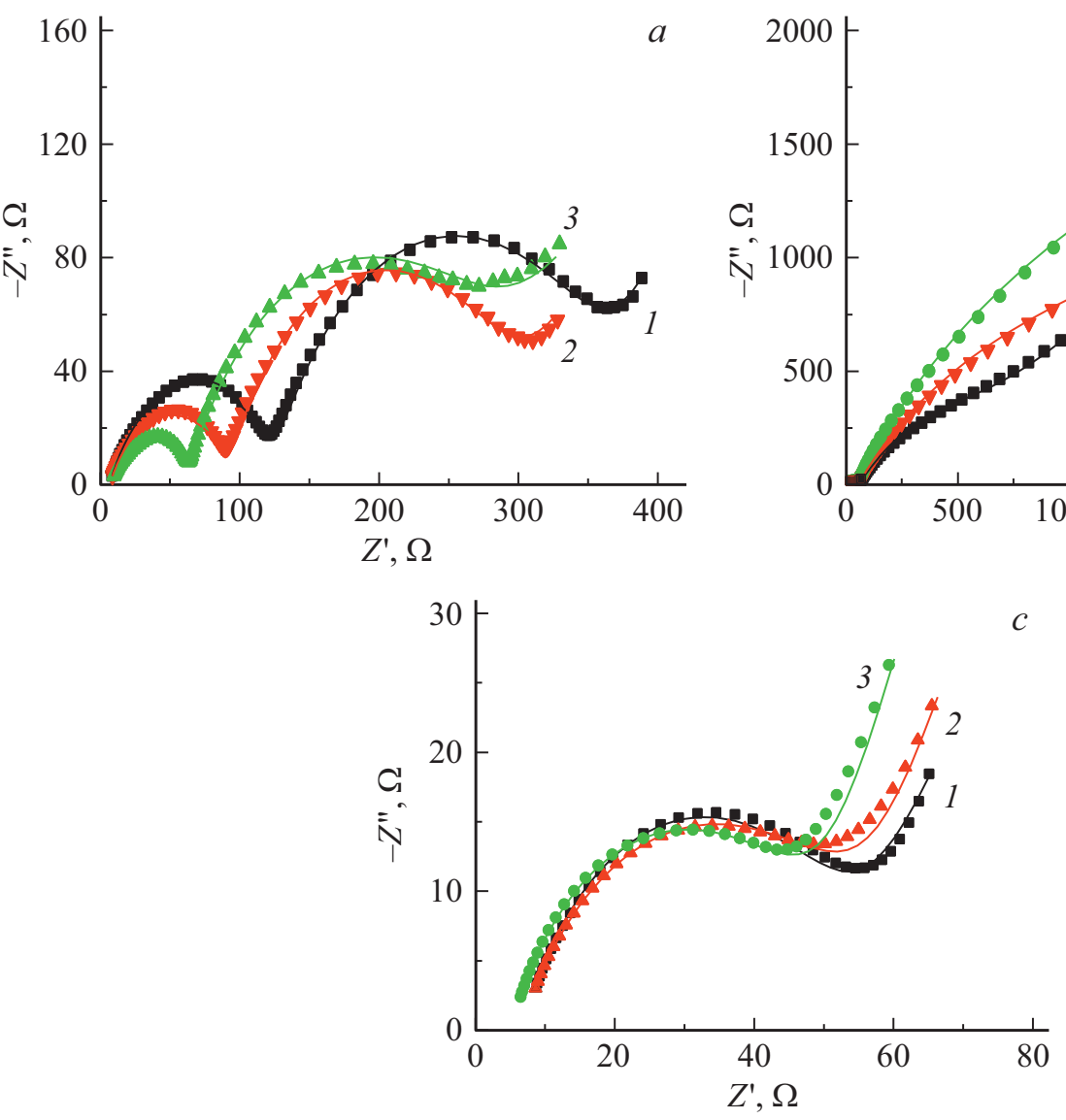

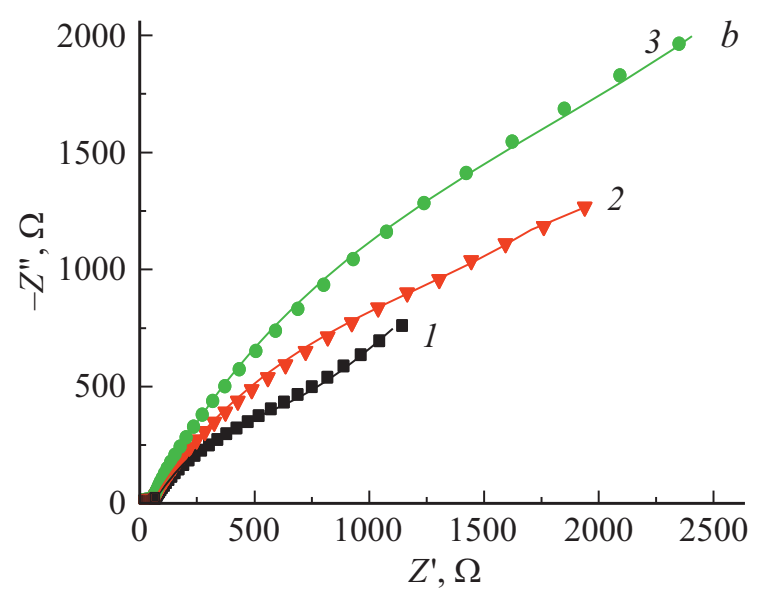

Рис. 4. Изменение годографов по мере увеличения номера цикла $(1,2,3): a-$ литированное состояние, $b-$ делитированное состояние, $c$ - высокочастотная область годографов в делитированном состоянии. Точки - экспериментальные данные, линии результаты расчета эквивалентной схемы.

границе $a-\mathrm{Li}_{x} \mathrm{Si} / c$-Si. После экстракции лития структура кремния изменяется, он становится аморфным, и следующие циклы протекают уже по однофазному механизму. Это отражается на форме зарядных кривых, которые приобретают более округлую форму и почти линейный наклонный участок. Необратимые потери первого цикла, связанные с образованием SEI, выше для электрода $\mathrm{Si} / \mathrm{C}$ (кулоновская эффективность 75\% по сравнению с $82 \%$ для Si-электрода). Такое поведение связано с увеличением площади поверхности за счет аморфного углерода. На втором и третьем циклах в обоих случаях потери падают, и кулоновская эффективность увеличивается до $96 \%$.

После каждого полуцикла внедрения или экстракции $\mathrm{Li}$ электрод отключался от стенда и релаксировал в режиме холостого хода в течение $\sim(15-20)$ ч. После этого проводились измерения импеданса. В результате релаксации напряжение на литированном электроде возрастало до постоянного значения $E_{r} \approx 0.2 \mathrm{~B}$. Неизменность потенциала во времени после релаксации указывает на то, что установилось равномерное по толщине распределение лития. Исходя из емкости $Q=1000 \mathrm{MA} \cdot$ ч/г по формуле $Q=960 x$ можно найти, что содержание лития в литированном образце соответствует стехиомет- рическому составу LiSi $(x \approx 1)$. Аналогичной процедуре подвергались образцы после полуцикла экстракции лития $(x \approx 0)$, который завершался при $E=2$ В. В этом случае после релаксации в режиме разомкнутой цепи напряжение на электроде падало и стабилизировалось на уровне $E_{r} \approx 0.8 \mathrm{~B}$.

\section{1. Импедансные измерения кремниевых образцов}

Измерения начинались со спектров импеданса $Z^{\prime}-Z^{\prime \prime}$, исходного (нелитированного) электрода. Стационарный потенциал электрода перед измерением был близок к $E=2$ В. На рис. 2 представлен полученный годограф в координатах Найквиста. В отсутствие внедренного лития годограф имеет простую форму, состоящую из дуги полуокружности, плавно переходящей в прямую линию в области низких частот.

Как видно из рис. 3, процесс литирования приводит к уменьшению импеданса и изменению формы годографа. На годографе рис. 3, $a$ четко различаются 2 полуокружности: в диапазоне частот от $100 \kappa$ ц до 100 Гц - несколько искаженная полуокружность малого диаметра, в диапазоне 100-0.025 Гц - полуокружность 


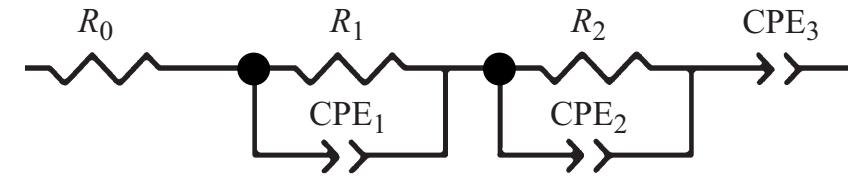

Рис. 5. Эквивалентная электрическая схема, моделирующая спектры импеданса Si-электродов.

большего диаметра. В области низких частот появляется короткий линейный участок. Делитирование приводит к увеличению импеданса (рис. 3,b). При этом вторая полуокружность, четко наблюдаемая в литированном состоянии, с уменьшением частоты переходит в прямую линию. Спектр импеданса для делитированного состояния в целом имеет форму, подобную наблюдавшейся для исходного электрода, однако в области высоких частот появляется четко сформировавшаяся полуокружность (рис. 3,c). Из сравнения годографов на рис. 3, $a$ и $b$ следует, что в литированном состоянии реакция тока на приложенное переменное напряжение малой амплитуды определяется кинетикой переноса заряда, а в делитированном - диффузионными процессами.

Спектры импеданса для последующих циклов (рис. 4) принципиально не отличаются от годографов для первого цикла, имеют аналогичную форму. По мере увеличения числа циклов наблюдается сдвиг годографов в область меньших значений омического сопротивления, что, вероятно, связано с разрыхлением материала.

Полученные спектры позволили предложить следующую эквивалентную электрическую схему, приведенную на рис. 5.

Схема представляет собой последовательное соединение сопротивления $R_{0}$, двух параллельных комбинаций сопротивления и элементов с постоянным сдвигом фазы $\left(R_{1} \| \mathrm{CPE}_{1}\right)$ и $\left(R_{2} \| \mathrm{CPE}_{2}\right)$, а также последовательно включенного элемента $\mathrm{CPE}_{3}$. Такие же или близкие эквивалентные схемы для кремниевых или композитных электродов использовались в работах [12,18-20]. Импеданс элемента с постоянным сдвигом фазы рассчитывается по формуле

$$
Z_{\mathrm{CPE}}=j / A \omega^{n},
$$

где $j-$ мнимая единица, $\sqrt{-1}, \omega=2 \pi \nu-$ круговая частота измерительного сигнала, $A$ - параметр, который в зависимости от показателя степени $n$ может соответствовать сопротивлению $(n=0)$, емкости $(n=+1)$, индуктивности $(n=-1)$ и коэффициенту импеданса Варбурга $(n=0.5)$ [21]. Параметры эквивалентной схемы, позволяющие получить наилучшее согласие с экспериментальными спектрами EIS для Si-электрода на первых трех циклах, представлены в табл. 2.

Первый элемент эквивалентной схемы - это coпротивление электролита $R_{0}$ (точнее, все омические сопротивления системы), которое равно величине высокочастотной отсечки, полученной экстраполяцией годографа на действительную ось. Из табл. 2 видно, что $R_{0}$
Таблица 2. Расчетные значения параметров эквивалентной схемы для годографов импеданса в литированном и делитированном состояниях $\mathrm{Si-электрода} \mathrm{для} \mathrm{первых} \mathrm{трех} \mathrm{циклов}$ заряда-разряда

\begin{tabular}{l|c|c|c|c|c|c}
\hline \multicolumn{1}{c|}{ Состояние } & \multicolumn{3}{c|}{ Литированное } & \multicolumn{3}{c}{ Делитированное } \\
\hline \multicolumn{1}{c|}{ Номер цикла } & 1 & 2 & 3 & 1 & 2 & 3 \\
\hline$R_{0}$, Ом & 6.7 & 6.8 & 8.5 & 6.4 & 6.2 & 6.1 \\
$A_{1}$, мкФ & 32.4 & 44.4 & 62.4 & 78.5 & 50.3 & 38.8 \\
$n_{1}$ & 0.67 & 0.64 & 0.63 & 0.68 & 0.64 & 0.68 \\
$R_{1}$, Ом & 120 & 87 & 53 & 50 & 49.6 & 43.8 \\
$A_{2}$, МкФ & 2800 & 2940 & 3110 & 2430 & 2080 & 1580 \\
$n_{2}$ & 0.77 & 0.78 & 0.78 & 0.69 & 0.74 & 0.76 \\
$R_{2}$, Ом & 230 & 204 & 201 & 617 & 1110 & 1800 \\
$A_{3}, \mathrm{OM}^{-1} \cdot \Gamma_{ц}^{-n 3}$ & 0.049 & 0.070 & 0.035 & 0.0061 & 0.0042 & 0.0031 \\
$n_{3}$ & 0.61 & 0.63 & 0.53 & 0.6 & 0.58 & 0.64
\end{tabular}

практически не зависит от потенциала и номера цикла. Первая параллельная комбинация сопротивления $R_{1}$ и элемента с постоянным сдвигом фазы $\mathrm{CPE}_{1}$ моделирует полуокружность, наблюдаемую при наиболее высокой частоте. Следующая параллельная комбинация $R_{2}$ и $\mathrm{CPE}_{2}$ относится ко второй четко различимой полуокружности в литированном состоянии и к дуге полуокружности (100-0.25 Гц) в делитированном (рис. 3, 4). Несмотря на отличие показателей степени $n_{1}$ и $n_{2}$ от единицы, оба элемента постоянной фазы, $\mathrm{CPE}_{1}$ и $\mathrm{CPE}_{2}$, можно интерпретировать как емкости, аналогично тому, как это делается в большинстве работ $[12,20]$. Отклонение показателя степени от единицы связывают с разными причинами, например, с шероховатой поверхностью электрода [22] или слоистой структурой твердофазной пленки SEI [23-25]. Емкость $A_{2}$ намного больше, чем $A_{1}$, на основании чего можно предположить, что первая параллельная комбинация моделирует SEI, a вторая - двойной электрический слой. Действительно, емкость двойного электрического слоя, как правило, на 1-2 порядока больше геометрической емкости пленки SEI [26]. В пользу сделанного предположения говорит также сравнение спектров для исходного электрода и электрода, подвергшегося циклическому внедрению и экстракции Li. Из рис. 2 и 3 можно видеть, что появление полуокружности в области высоких частот происходит только после первого цикла литирования и сохраняется в делитированном состоянии, т.е. связано с формированием SEI. Стоит отметить, что высокочастотная полуокружность присуща многим литиевым электродным системам, в которых есть пассивная пленка SEI $[8,23,27]$. Емкость двойного электрического слоя практически не зависит от потенциала [23], в то время как сопротивление переноса заряда, как и в нашем случае, резко возрастает при его увеличении. Таким образом, можно считать, что сопротивление $R_{1}$ характеризует транспорт ионов $\mathrm{Li}^{+}$через SEI, а параметр $A_{1}$ - ее геометрическую емкость. $R_{2}$ следует интерпретировать 

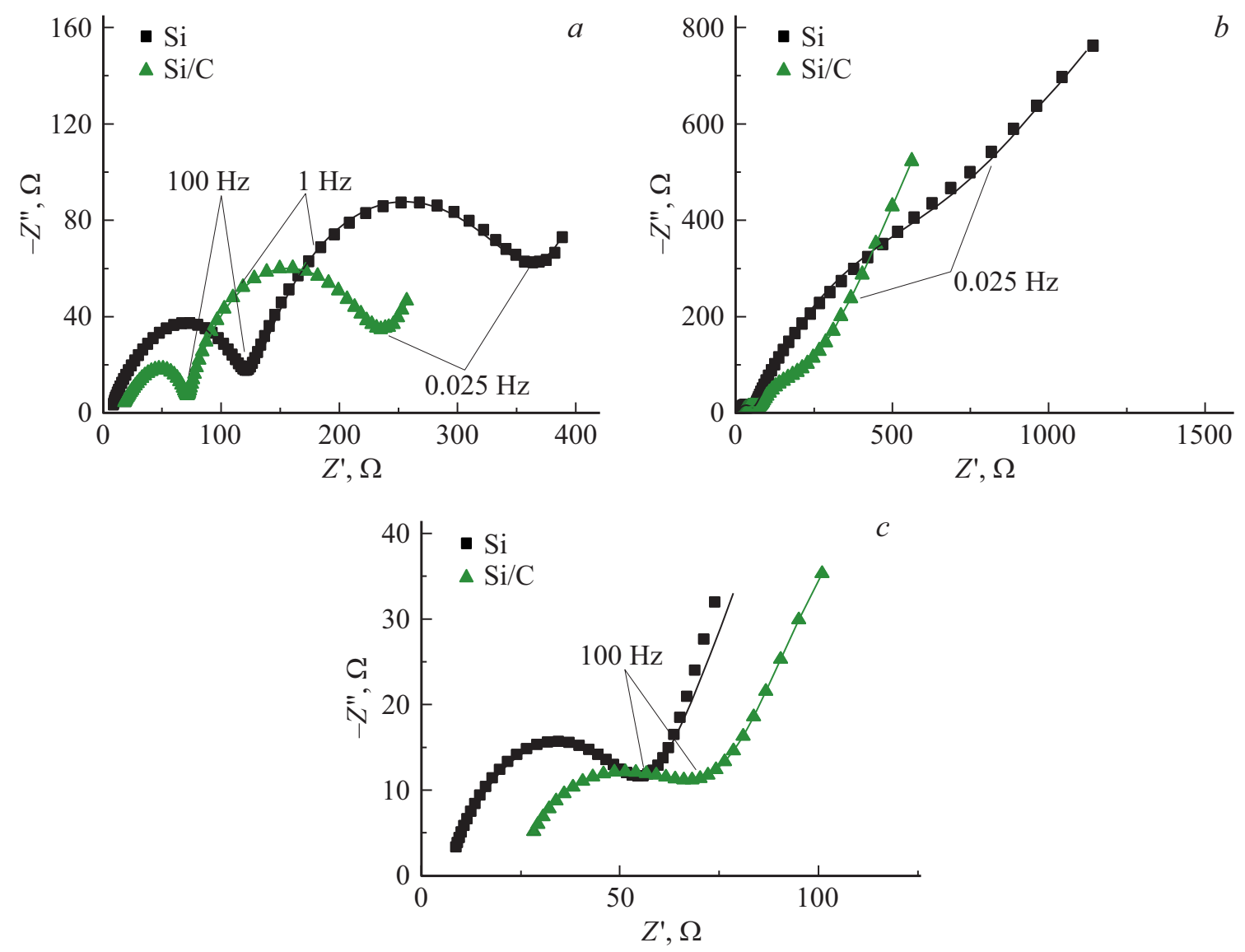

Рис. 6. Годографы импеданса электродов из $\mathrm{Si}$ и $\mathrm{Si} / \mathrm{C}$ на первом цикле: $a-$ литированное состояние, $b-$ делитированное состояние; $c$ - высокочастотная область годографов в делитированном состоянии.

как сопротивление переноса заряда (скорости реакции восстановления/окисления лития), а $A_{2}$ - как емкость двойного электрического слоя.

Последний элемент, $\mathrm{CPE}_{3}$, моделирует низкочастотный линейный участок (импеданс Варбурга), который характеризует диффузию атомов лития в объеме кремния. Из рис. 3,4 видно, что импеданс в области низких частот в делитированном состоянии существенно выше, чем в литированном, что, согласно формуле (1), соответствует более низким значениям параметра $A_{3}$.

\section{2. Импедансные измерения карбонизированных образцов}

На рис. 6 приведены годографы импеданса первого цикла для чисто кремниевого и карбонизированного электродов. Из них видно, что карбонизация приводит к уменьшению импеданса. Форма частотной зависимости импеданса для композитного электрода совпадает с таковой для кремниевого электрода, поэтому может быть промоделирована с использованием той же эквивалентной электрической схемы рис. 5. Значения параметров этой схемы для первых трех циклов приведены в табл. 3.
Таблица 3. Расчетные значения параметров эквивалентной

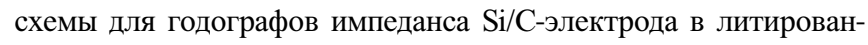
ном и делитированном состояниях

\begin{tabular}{l|c|c|c|c|c|c}
\hline \multicolumn{1}{c|}{ Состояние } & \multicolumn{3}{c|}{ Литированное } & \multicolumn{3}{c}{ Делитированное } \\
\hline \multicolumn{1}{c|}{ Номер цикла } & 1 & 2 & 3 & 1 & 2 & 3 \\
\hline$R_{0}$, Ом & 16.1 & 17.5 & 20 & 24.5 & 30.2 & 33.3 \\
$A_{1}$, Мк $\Phi$ & 52.5 & 56.8 & 88 & 66.6 & 78 & 73.4 \\
$n_{1}$ & 0.67 & 0.61 & 0.59 & 0.62 & 0.65 & 0.59 \\
$R_{1}$, Ом & 58.3 & 54.7 & 46.7 & 49.7 & 25 & 29.3 \\
$A_{2}$, Мк $\Phi$ & 2230 & 2560 & 2340 & 3120 & 3300 & 3110 \\
$n_{2}$ & 0.83 & 0.83 & 0.82 & 0.7 & 0.64 & 0.73 \\
$R_{2}, \mathrm{OM}^{-1} \cdot \Gamma_{ц}{ }^{-n 3}$ & 148 & 113 & 136 & 226 & 200 & 185 \\
$A_{3}, \mathrm{OM}^{-081}$ & 0.089 & 0.089 & 0.0073 & 0.014 & 0.0079 \\
$n_{3}$ & 0.55 & 0.51 & 0.55 & 0.6 & 0.62 & 0.53
\end{tabular}

\section{4. Обсуждение результатов}

На рис. 7 построены зависимости сопротивлений $R_{1}$ и $R_{2}$ от номера цикла. Из них видно, что процесс карбонизации пористого Si-электрода приводит к уменьшению сопротивлений $R_{1}$ и $R_{2}$ как в литированном, так и в делитированном состоянии. Для обоих состояний 

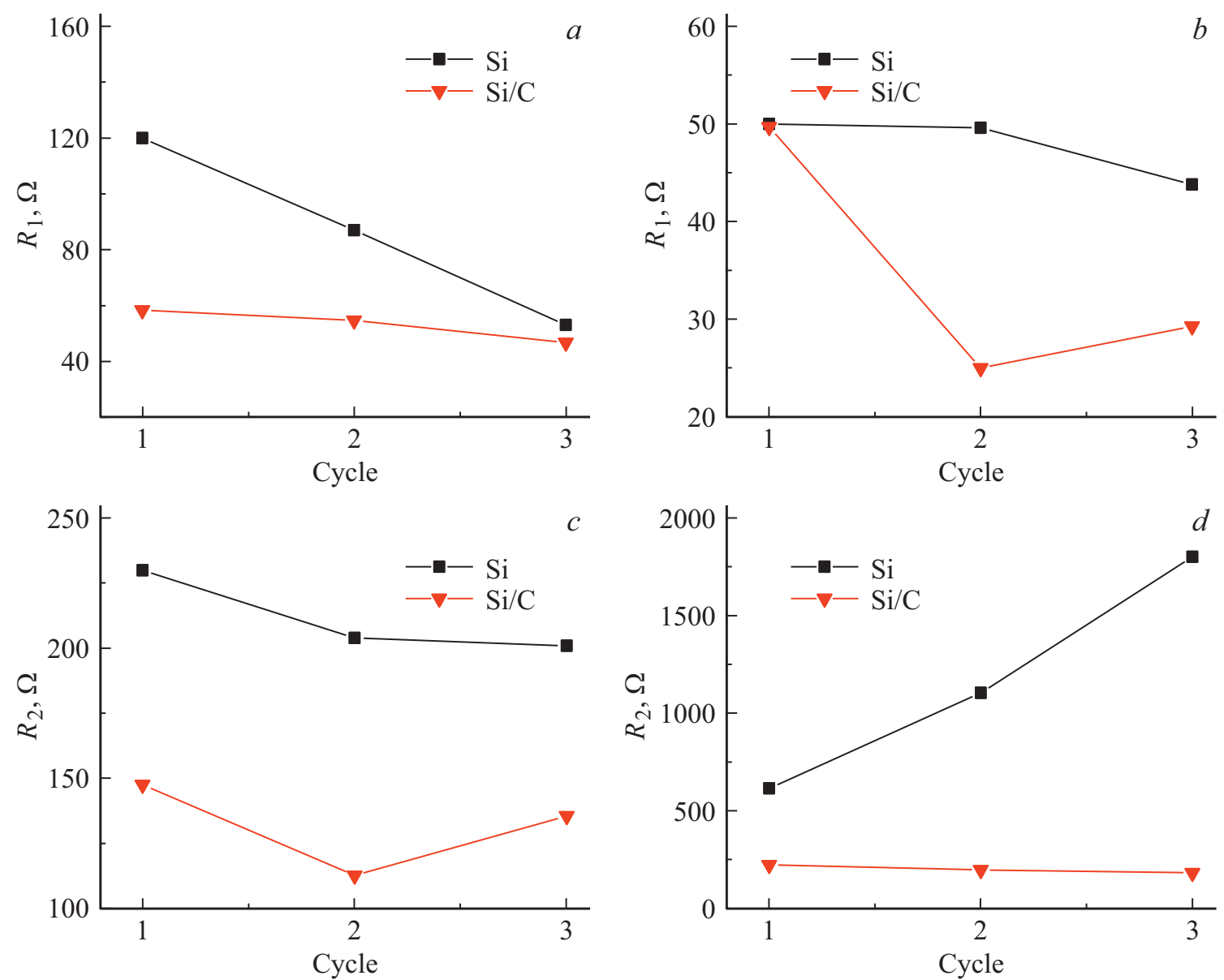

Рис. 7. Влияние карбонизации на сопротивления $R_{1}(a, b)$ и $R_{2}(c, d):(a, c)$ - литированное состояние, $(b, d)-$ делитированное состояние электрода.
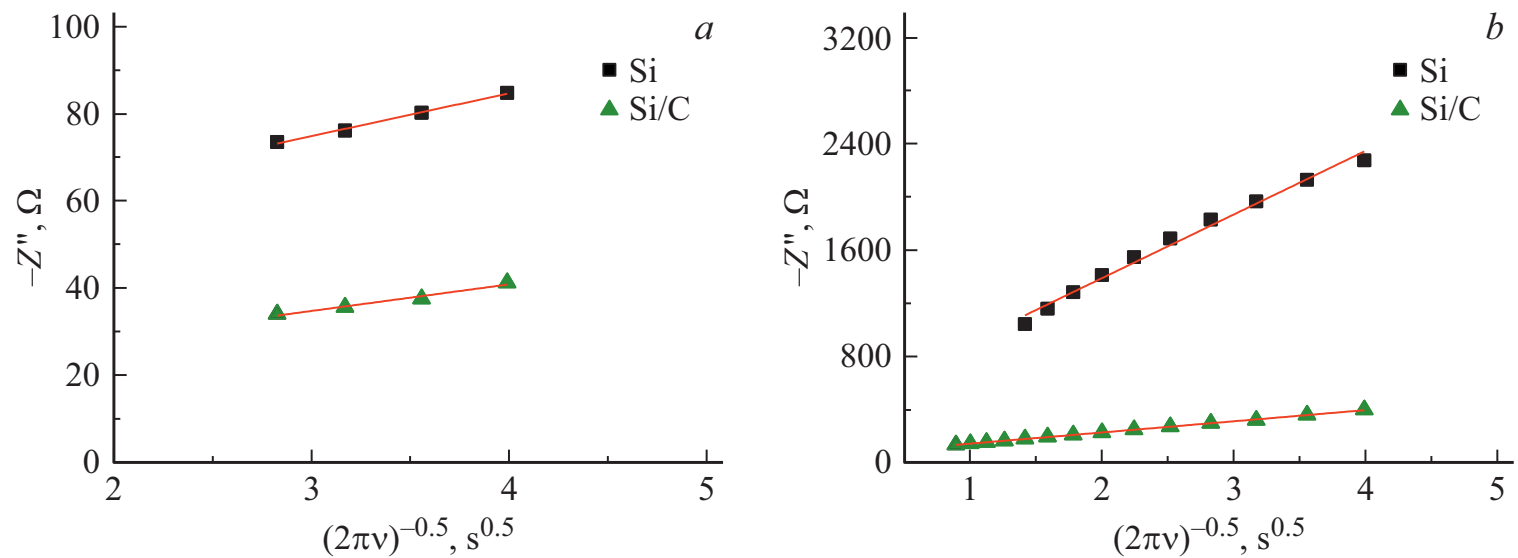

Рис. 8. Зависимости мнимой составляющей импеданса от $\sqrt{1 / 2 \pi v}: a-$ литированное состояние, $b$ - делитированное состояние

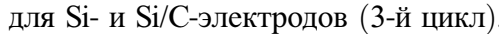

емкость SEI $A_{1}$ (табл. 2 и 3) в результате карбонизации возрастает, что обусловлено увеличением площади поверхности и согласуется с возросшими необратимыми потерями емкости на первом цикле в $\mathrm{Si} / \mathrm{C}$. Увеличением площади, по-видимому, можно объяснить и снижение сопротивления $R_{1}$. Независимо от наличия или отсутствия углеродного покрытия, в делитированном состоянии сопротивление SEI в среднем ниже, чем в литированном, что позволяет думать о уменьшении толщины SEI при экстракции лития. Последнее согласуется с эффектом циклического изменения толщины SEI, наблюдавшимся в работах $[28,29]$. Уменьшение сопротивления $R_{2}$, связанного с электрохимической реакцией на поверхности кремниевых зерен, т. е. переносом заряда, можно 
Таблица 4. Эффективные коэффициенты диффузии лития в кремниевом и кремний-углеродном электродах, найденные с помощью EIS

\begin{tabular}{c|c|c|c|c|c|c}
\hline Состояние & \multicolumn{3}{|c|}{ Литированное } & \multicolumn{3}{c}{ Делитированное } \\
\hline Параметр & $W, \mathrm{OM} \cdot \mathrm{c}^{-0.5}$ & $d E / d Q$, Ом/c & $D, \mathrm{~cm}^{2} / \mathrm{c}$ & $W, \mathrm{OM} \cdot \mathrm{c}^{-0.5}$ & $d E / d Q, \mathrm{Oм} / \mathrm{c}$ & $D, \mathrm{~cm}^{2} / \mathrm{c}$ \\
\hline $\mathrm{Si}$ & 9.84 & -0.0270 & $2.6 \cdot 10^{-10}$ & 479 & 0.208 & $6.5 \cdot 10^{-12}$ \\
$\mathrm{Si} / \mathrm{C}$ & 6.11 & -0.0414 & $1.7 \cdot 10^{-9}$ & 84.2 & 0.206 & $2.2 \cdot 10^{-10}$
\end{tabular}

объяснить повышением электронной проводимости в результате карбонизации.

Полученные данные EIS дают возможность определить эффективный коэффициент диффузии лития как в кремниевом, так и в композитном электродах. Связная структура спеченного материала позволяет рассматривать его как однородную в макромасштабе среду, которая содержит дефекты в виде пор. Полагая, что внедрение и экстракция лития в $\mathrm{Si}-$ и $\mathrm{Si} / \mathrm{C}$-электроды происходят по закону для полубесконечной диффузии [30], из прямолинейного низкочастотного участка годографа можно определить наклон зависимости для мнимой части импеданса $Z^{\prime \prime}=f\left(\omega^{-0.5}\right)$ :

$$
-Z^{\prime \prime}=\frac{W}{\sqrt{2 \pi \nu}},
$$

где $W$ - константа Варбурга.

Из рис. 8 видно, что полученные зависимости хорошо аппроксимируются прямой. Постоянная Варбурга, в свою очередь, связана, с зависимостью равновесного потенциала $E(\mathrm{~B})$ от концентрации диффундирующего лития $c\left(\right.$ моль/см$\left.{ }^{3}\right)$ выражением [30]

$$
W=\frac{-d E / d c}{F S \sqrt{2 D}}
$$

где $D\left(\mathrm{~cm}^{2} / \mathrm{c}\right)$ эффективный коэффициент диффузии атомов лития в кремнии, $F-$ постоянная Фарадея (Кл/моль), $S$ ( $\left.\mathrm{cm}^{2}\right)$ - номинальная площадь электрода. $d E / d c$ можно выразить через $d E / d Q$ с помощью выражения

$$
d c=\frac{d Q}{F L S} .
$$

Комбинация уравнений (3) и (4) дает следующее выражение для коэффициента диффузии:

$$
D=\frac{L^{2}(d E / d Q)^{2}}{2 W^{2}},
$$

где $L$ - толщина электрода в см.

Величину $d E / d Q$ можно определить из квазиравновесных зарядных и разрядных кривых рис. 1. Найденные значения $d E / d Q$ для третьего цикла вблизи $E=0.2$ и $0.8 \mathrm{~B}$, коэффициенты Варбурга $W$ и полученные из них с помощью формулы (5) значения коэффициента диффузии лития $D$ сведены в табл. 4. Хорошо видно, что в литированном состоянии $D$ намного выше, чем в делитированном, т.е. $D$ зависит от содержания лития в сплаве $\mathrm{Li}_{x} \mathrm{Si}$ и от соответствующего потенциала $E$. Причиной этого может служить увеличение объема, происходящее при образовании сплава $\mathrm{Li} \mathrm{c}$ кремнием. Концентрационная зависимость сильнее выражена для чисто кремниевого электрода, чем для композитного. В последнем случае коэффициент диффузии в делитированном состоянии существенно (в $\sim 34$ раза) возрастает по сравнению с $\mathrm{Si}$, что можно приписать более высокой подвижности лития в углеродных материалах. В целом найденные нами величины $D$ лежат в диапазоне $10^{-12}-10^{-10} \mathrm{~cm}^{2} / \mathrm{c}$, что согласуется с литературными данными для кремния [31].

\section{5. Заключение}

С помощью метода электрохимической импедансной спектроскопии установлено, что чисто кремниевым макропористым электродам, полученным спеканием нанопорошка, как и подвергшимся дополнительной модификации углеродом, присуща кинетика электрохимических процессов, характерная для других материалов $\mathrm{Si}$ и $\mathrm{Si} / \mathrm{C}$ в виде тонких аморфных пленок кремния или композитов для намазной технологии. Исследованные образцы обнаруживают сильную концентрационную зависимость эффективного коэффициента диффузии лития и его существенное увеличение в результате карбонизации. Композитные $\mathrm{Si} / \mathrm{C}$-электроды обладают более низким по сравнению с $\mathrm{Si}$, сопротивлением переноса заряда и меньшим сопротивлением пленки SEI.

\section{Конфликт интересов}

Авторы заявляют, что у них нет конфликта интересов.

\section{Список литературы}

[1] J.R. Szczecha, Song Jin. Energ. Environ. Sci., 4, 56 (2011)

[2] Du Fei-Hu, Wang Kai-Xue, Chen Jie-Sheng. J. Mater. Chem. A, 4, 32 (2016).

[3] H. Foll, H. Hartz, E.K. Ossei-Wusu, J. Carstensen, O. Riemenschneider. Phys. Status Solidi RRL, 4, 4 (2010).

[4] Г.В. Ли, Е.В. Астрова, А.М. Румянцев, В.Б. Воронков, А.В. Парфеньева, В.А. Толмачев, Т.Л. Кулова, А.М. Скундин. Электрохимия, 51 (10), 1020 (2015).

[5] Liu Xuyan, Zhu Xinjie, Pan Deng. Royal Soc. Open Sci., 5 (6), 1 (2018). 
[6] Dou Fei, Shi Liyi, Chen Guorong, Zhang Dengsong. Electrochem. Energy Rev., 2 (1), 149 (2019).

[7] M.D. Levi, D. Aurbach. Phys. Chem., 101, 4630 (1997).

[8] А.В. Чуриков, К.И. Придатко, А.В. Иванищев, И.А. Иванищев, И.М. Гамаюнова, К.В. Запсис, В.О. Сычева. Электрохимия, 44 (5), 594 (2008).

[9] S.S. Zhang, K. Xu, T.R. Jow. Electrochim. Acta, 51, 1636 (2006).

[10] E. Pollak, G. Salitra, V. Baranchugov, D. Aurbach. J. Phys. Chem., 111, 11437 (2007).

[11] W. Weppner, R.A. Huggins. J. Electrochem. Soc., 124 (10), 1569 (1977).

[12] T.L. Kulova, Yu.V. Pleskov, A.M. Skundin, E.I. Terukov, O.I. Kon'kov. Russ. J. Electrochem., 42 (7), 708 (2006).

[13] K. Yoshimura, J. Suzuki, K. Sekine, T. Takamura. J. Power Sources, 146, 445 (2005).

[14] Е.В. Астрова, В.Б. Воронков, А.В. Нащекин, А.В. Парфентьева, Д.А. Ложкина, М.В. Томкович, Ю.А. Кукушкина. ФТП, 53, 540 (2019).

[15] Е.В. Астрова, В.Б. Воронков, А.М. Румянцев, А.В. Нащекин, А.В. Парфентьева, Д.А. Ложкина. Электрохимия, 55 (3), 318 (2019)

[16] M.N. Obrovac, L. Christensen. Electrochem. Solid-State Lett., 7, 93 (2004).

[17] M. Pharr, K. Zhao, X. Wang, Z. Suo, J.J. Vlassak. Nano Lett., 12, 5039 (2012).

[18] R. Ruffo, S.S. Hong, C.K. Chan, R.A. Huggins, Y. Cui. J. Phys. Chem., 113 (26), 11390 (2009).

[19] J. Guo, A. Sun, X. Chen, C. Wang, A. Manivannan. Electrochim. Acta, 56, 3981 (2011).

[20] Y. Yamada, Y. Iriyama. J. Electrochem. Soc., 157 (1), 26 (2010).

[21] З.Б. Стойнов, Б.М. Графов, Б.С. Савова-Стойнова, В.В. Елкин. Электрохимический импеданс (М., Наука,1991).

[22] Электроаналитические методы. Теория и практика, под ред. Ф. Шольца (М., БИНОМ, Лаборатория знаний, 2006).

[23] M. Umeda, K. Dokko, Y. Fujita, M. Mohamedi, I. Uchida, J.R. Selman. Electrochim. Acta, 47, 885 (2001).

[24] D. Aurbach, I. Weissman, A. Schechter, H. Cohen. Langmuir, 12, 3991 (1996).

[25] C. Wang, A.J. Appleby, F.E. Little. Electrochim. Acta, 46, 1793 (2001).

[26] А.В. Иванищев, А.В. Чуриков. Электрохимия, 44 (5), 553 (2008).

[27] D. Aurbach, K. Gamolsky, B. Markovsky, G. Salitra, Y. Gofen, U. Heider, R. Oesten, M. Schmidt. J. Electrochem. Soc., 147 (4), 1322 (2000).

[28] D. Aurbach, B. Markovsky, I. Weissman, E. Levi, Y. Ein-Ely. Electrochim. Acta, 45, 67 (1999).

[29] C.K. Chan, R. Ruffo, S.S. Hong, Y. Cui. J. Power Sources, 189, 1132 (2009).

[30] C. Ho, I.D. Raistrick, R.A. Huggins. J. Electrochem. Soc., 127, 343 (1980)

[31] F. Ozanam, M. Rosso. Mater. Sci. Engin., 213, 2 (2016).

\section{Impedance spectroscopy of porous silicon and silicon-carbon anodes obtained by sintering}

\section{D.A. Lozhkina, A.M. Rumyantsev, E.V. Astrova}

loffe Institute,

194021 St. Petersburg, Russia

Abstract Dry sintered macroporous $\mathrm{Si}$ electrodes for Li-ion batteries are first studied using spectral impedance measurements. The obtained spectra in the lithiated and delithiated state are modeled by an equivalent electrical circuit, the parameters of which make it possible to reveal the role of electrochemical processes caused by the surface layer of solid-phase electrolyte (SEI), a double electric layer, and diffusion in the solid phase of the electrode material. It was shown that the effective diffusion coefficient of $\mathrm{Li}$ in $\mathrm{Si}$ increases with rising degree of lithiation from $D=6.5 \cdot 10^{-12}$ to $2.6 \cdot 10^{-10} \mathrm{~cm}^{2} / \mathrm{s}$. The effect of carbonization by sucrose pyrolysis was studied, which led to a decrease in impedance and an increase in the diffusion coefficient of lithium to $D=2.2 \cdot 10^{-10}-1.7 \cdot 10^{-9} \mathrm{~cm}^{2} / \mathrm{s}$.

Редактор Л.В. Шаронова 